\title{
The Effect of Ultrasound-Guided Erector Spinae Plane Block Combined with Dexmedetomidine on Postoperative Analgesia in Patients Undergoing Modified Radical Mastectomy: A Randomized Controlled Trial
}

\author{
Xunxun Wang · Guo Ran · Xia Chen · Cuiyu Xie · Jing Wang • \\ Xuesheng Liu · Yao Lu (D) · Weiping Fang
}

Received: November 8, 2020 / Accepted: December 22, 2020 / Published online: January 21, 2021

(c) The Author(s) 2021

\begin{abstract}
Introduction: One of the most common malignancies in women worldwide is breast cancer. Erector spinae plane block (ESPB) can reduce pain after modified radical mastectomy for breast cancer. The duration of nerve block analgesia is limited if local anesthetic agents are used alone. The purpose of this study was to evaluate the effect of dexmedetomidine on postoperative analgesia during a single injection of local anesthetics.

Methods: In this double-blind, randomized study, 60 female American Society of Anesthesiologists (ASA) I-II patients undergoing modified radical mastectomy were randomized into two groups: ultrasound (US)-guided ESPB with $30 \mathrm{~mL}$ of $0.33 \%$ ropivacaine (group R) and USguided ESPB with $30 \mathrm{~mL}$ of dexmedetomidine plus $0.33 \%$ ropivacaine (group DR). US-guided ESPB at the T3 vertebral level was performed
\end{abstract}

X. Wang $\cdot$ X. Chen $\cdot$ C. Xie $\cdot$ J. Wang $\cdot$ X. Liu

Y. Lu $(\bowtie) \cdot$ W. Fang $(\bowtie)$

Department of Anesthesiology, The First Affiliated

Hospital of Anhui Medical University, Hefei, Anhui

Province, China

e-mail: luyao-mz@163.com

W. Fang

e-mail: planner@vip.sina.com

G. Ran

Department of Anesthesiology, Eye \& ENT Hospital, Fudan University, Shanghai, China preoperatively in all patients. The indicators were 1-, 6-, 12-, 24-, and 48-h visual analog scale (VAS) pain scores after surgery in the resting state and at 90-degree shoulder abduction. Other measures were a comparison of intraoperative sufentanil and remifentanil, postoperative nausea and vomiting (PONV), flurbiprofen consumption, the lengths of post-anesthesia care unit (PACU) stay and hospital stay, postoperative bradycardia, and hypotension.

Results: The VAS pain score was lower in group DR than group $\mathrm{R}$ at any time in the resting state, except at $1 \mathrm{~h}$ after surgery. The VAS pain score was lower in group DR than group R at 12 and $24 \mathrm{~h}$ in an active state after surgery $(P<0.05$ for each time interval). The intraoperative dosages of remifentanil and sufentanil in group DR were lower than that in group $\mathrm{R}$. The postoperative dosage of flurbiprofen in group DR was lower than that in group $\mathrm{R}(P=0.038)$. The lengths of PACU stay were longer in group DR than in group R. No significant difference was found in PONV and hospital stay between the two groups. No sinus bradycardia or hypotension after surgery occurred in the two groups.

Conclusions: Dexmedetomidine as an adjunctive to ESPB can effectively relieve pain and significantly reduce the need for opioids during modified radical mastectomy for breast cancer.

Trial Registration: The study was registered in the Chinese Clinical Trial Registry (ChiCTR2000031134, principal investigator: Yao Lu, date of registration: 2020-3-22). 
Keywords: Dexmedetomidine; Erector spinae plane block; Mastectomy; Postoperative analgesia; Ultrasound

\section{Key Summary Points}

Why carry out this study?

Breast surgery is a common surgery, and more than half who experience breast cancer surgery develop postoperative chronic pain.

Ultrasound (US)-guided erector spinae plane block (ESPB) is a new analgesic technique proposed by Forero et al. Dexmedetomidine-assisted local anesthetic agents accelerated the onset and extended the duration of block in brachial plexus block.

We hypothesized that ESPB with dexmedetomidine $\left(1 \mu \mathrm{g} / \mathrm{kg}^{-1}\right)$ had better analgesic effect than ESPB alone in breast cancer surgery.

\section{What was learned from the study?}

This study revealed that dexmedetomidine $\left(1 \mu \mathrm{g} / \mathrm{kg}^{-1}\right)$ combined with $0.33 \%$ ropivacaine ESPB can better provide postoperative analgesia, and reduce intraoperative opioid consumption.

Dexmedetomidine $\left(1 \mu \mathrm{g} / \mathrm{kg}^{-1}\right)$ combined with $0.33 \%$ ropivacaine ESPB can better provide postoperative analgesia than without dexmedetomidine performance.

Dexmedetomidine combined with ESPB effectively improves postoperative analgesia and comfort level in patients undergoing modified radical mastectomy.

\section{DIGITAL FEATURES}

This article is published with digital features, including a summary slide, to facilitate understanding of the article. To view digital features for this article, go to https://doi.org/10. 6084/m9.figshare.13401566.

\section{INTRODUCTION}

One of the most common malignancies in women worldwide is breast cancer. Breast cancer in women statistics reveal that one in eight women in the United States will develop breast cancer in their lifetime. Therefore, breast surgery is a common surgery [1]. Unfortunately, more than half who experience breast cancer surgery develop chronic postoperative pain [2].

There are some regional nerve blocks in breast cancer for postoperative analgesia [3]. Thoracic epidural [4], interscalene brachial plexus [5], paravertebral [6], and pectoral nerve blocks (pecs I and II) [7] have achieved good results in postoperative analgesia for breast cancer. Ultrasound (US)-guided erector spinae plane block (ESPB) is a new analgesic technique proposed by Forero et al. [8]. Several case studies $[9,10]$ and a clinical trial $[11]$ reported that ESPB can reduce pain after modified radical mastectomy for breast cancer. However, despite the use of long-acting local anesthetic agents, the duration of anesthesia is maintained for $8-12 \mathrm{~h}$ [12]. Dexmedetomidine is a highly selective alpha-2 adrenal receptor agonist [13]. Notably, three recent meta-analyses reported that dexmedetomidine-assisted local anesthetic agents accelerated the onset and extended the duration of block in brachial plexus block [14-16]. However, there has been no report on the efficacy of dexmedetomidine combined with local anesthetic agents in ESPB. This study aimed to compare the effect of dexmedetomidine as an adjuvant combined with ESPB in breast cancer surgery.

\section{METHODS}

\section{Study Participants}

This study was approved by the ethics committee of The First Affiliated Hospital of Anhui Medical University, Hefei, Anhui Province, 
China, in May 2020 (PJ2020-06-08), and the study was registered in the Chinese Clinical Trial Registry (ChiCTR2000031134). The study protocol was performed in accordance with the Declaration of Helsinki. One day before the surgery, all patients were evaluated, and all patients signed a written informed consent to participate in the trial. A total of 60 female patients aged 28-70 years with ASA I-II who were scheduled for modified radical mastectomy for breast cancer between May and August 2020 were included in this study. The exclusion criteria included coagulation disorders, nerve block site infection, history of chronic pain medication use, sinus bradycardia, and atrioventricular block.

\section{Random Selection of Patients}

The study participants were randomly grouped on a scale of $1: 1$, using a computer-generated list of random numbers. The distribution results were sealed in an opaque envelope and kept by the study administrator. On the day of surgery, the study manager handed the envelope to the anesthesiologist (A) who dispensed the anesthetic fluid. Dexmedetomidine hydrochloride $(0.2 \mathrm{mg} / \mathrm{mL})$ obtained from Yangtze River Pharmaceutical Group Co., Ltd. was used in this study without preservatives. The patients were randomly assigned to two groups: the ropivacaine group (group R) and the dexmedetomidine plus ropivacaine group (group DR), with 30 patients in each group. On the day of surgery, noninvasive blood pressure, electrocardiogram, and oxygen saturation were monitored, and the patients received an indwelling intravenous needle after entering the operating room. Bispectral index monitoring was also monitored in all patients. All the monitoring data after entering the operating room were recorded. Before nerve block, all patients received intravenous sedation with midazolam at a dose of $0.05 \mathrm{mg} / \mathrm{kg}$ and a maximum dose of $3 \mathrm{mg}$. For each patient selected randomly, an anesthesiologist (A) obtained the patient data and prepared a total of $30 \mathrm{~mL}$ of $0.33 \%$ ropivacaine or $30 \mathrm{~mL}$ of $0.33 \%$ ropivacaine with dexmedetomidine $(1 \mu \mathrm{g} / \mathrm{kg})$. In addition, another $5 \mathrm{~mL}$ of $0.9 \%$ isotonic saline was prepared for positioning. The anesthesiologist at the front handed a syringe full of liquid medicine to a particular anesthesiologist (B) who had mastered the block without knowing the patient group.

\section{Spinal Erector Block Process}

The patients were placed in the lateral lying position on the affected side. For the first group of patients, a professional anesthesiologist placed a US (M-Turbo, Bothwell, USA) with a $5-\mathrm{cm}, 10-\mathrm{MHz}$ linear probe or a $2-5-\mathrm{MHz}$ curved array probe longitudinally at the T3 level of the spine; then, the probe was positioned $2-3 \mathrm{~cm}$ from the midline of the spine [17]. The ESPB involved injecting the local anesthetic agents in the fascial plane to the depth of the erector spinae muscles and between the transverse processes [18]. A 22-G, $0.7 \times 80-\mathrm{mm}$, insulated facet-tip needle (Conde Lai Group, Shanghai, China) was used during all blocks. The correct apical position was established deep into the plane of the erector spinae muscle, and the transverse process was covered by trapezius, rhomboid, and erector spinae muscles. The correct position of the needle tip was verified by injecting approximately $1 \mathrm{~mL}$ of $0.9 \%$ normal saline from caudad to cephalad. After determining the correct tip position, the anesthesiologist (B) slowly pushed in $30 \mathrm{~mL}$ of $0.33 \%$ ropivacaine, and longitudinal fluid diffusion was observed between the erector spinae muscle and the transverse process (Fig. 1). In the second group, the same procedure was repeated using $30 \mathrm{~mL}$ of $0.33 \%$ ropivacaine supplemented with dexmedetomidine. The patient was placed in the supine position after the nerve block was completed.

\section{Standard Procedure for General Anesthesia}

After a 5-min preoxygenation, anesthesia was induced with $0.1 \mathrm{mg} / \mathrm{kg}$ of dezocine, $2-3 \mathrm{mg} / \mathrm{kg}$ of etomidate, and $0.3-0.5 \mu \mathrm{g} / \mathrm{kg}$ of sufentanil intravenously in the two groups after the nerve block was completed. Laryngeal mask 

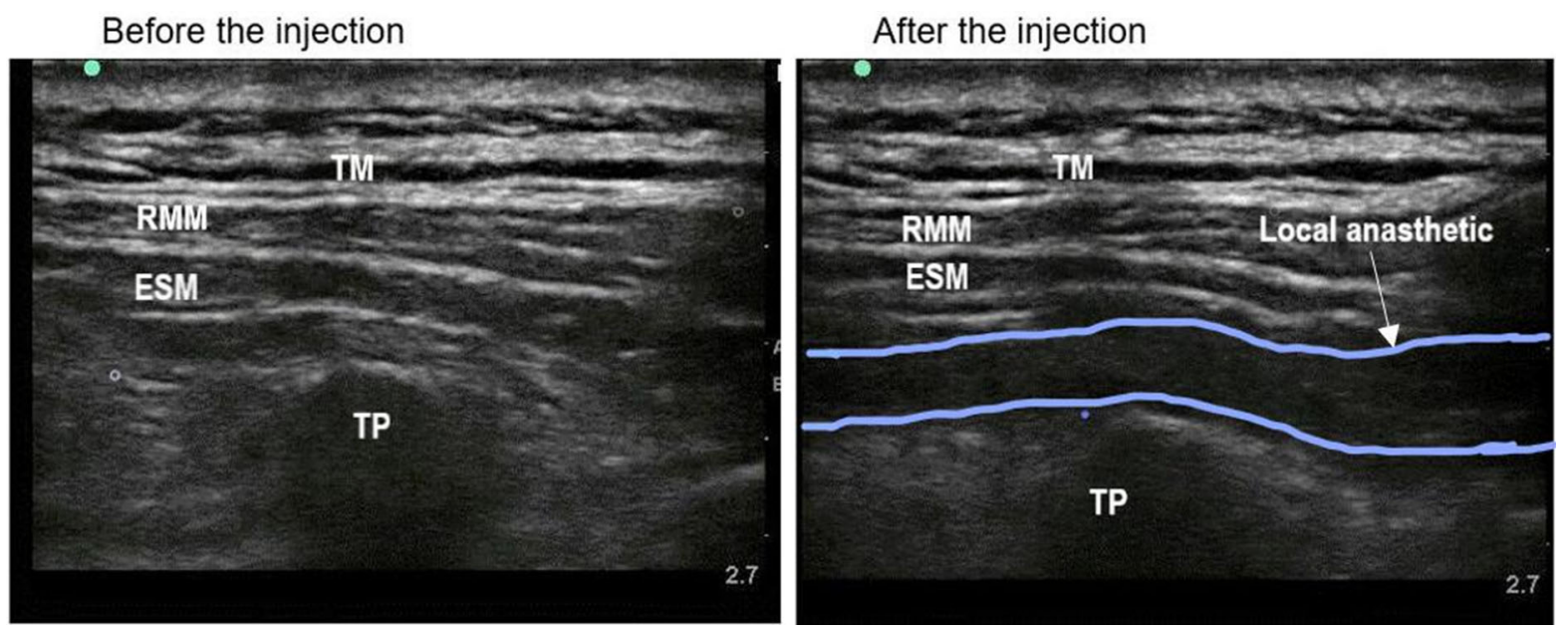

Fig. 1 Horizontal ultrasound imaging of the erector spinae plane block. $T M$ trapezius muscle; $R M M$ rhomboid muscle; ESM erector spinae muscle; TP transverse processes of the T3 vertebra

placement was completed after the use of $0.2-0.4 \mathrm{mg} / \mathrm{kg}$ of cisatracurium or $0.6-0.9 \mathrm{mg} /$ $\mathrm{kg}$ of rocuronium bromide. To maintain anesthesia in the patients, $4-6 \mathrm{mg} / \mathrm{kg}$ of propofol and $0.1-1 \mu \mathrm{g} / \mathrm{kg}$ of remifentanil were used. Cisatracurium or rocuronium was maintained for 40-60 min intraoperatively. The anesthesiologist injected $0.2 \mu \mathrm{g} / \mathrm{kg}$ of sufentanil intravenously when the patient's hemodynamic parameters exceeded $20 \%$ of the baseline. Patients were given $0.3 \mathrm{mg}$ of atropine at a heart rate of $<50$ beats per minute. The bispectral index system value during anesthesia maintenance was between 40 and 60. Patients were monitored using a Mindray T6 workstation. Intraoperative monitoring included noninvasive blood pressure, electrocardiogram, oxygen saturation, and respiratory carbon dioxide.

Postoperative pain was assessed using a visual analog scale (VAS) on a scale of 0 (no pain) to 10 (the worst pain imaginable). In addition, patients with a pain scale of $>4$ were given $50 \mathrm{mg}$ of flurbiprofen. Opioids are not routinely used for postoperative analgesia in our hospital. All patients were followed up by an anesthesiologist (C) who was blinded to the group allocation.

\section{Outcome Measures}

VAS pain scores were recorded at 1, 6, 12, 24, and $48 \mathrm{~h}$ after surgery by an anesthesiologist
(C) who was blinded to the patient group. The primary outcome was the dosage of flurbiprofen at $48 \mathrm{~h}$ after surgery. The VAS scores at rest and at 90-degree shoulder abduction after surgery were recorded. Secondary measures were a comparison of intraoperative and post-anesthesia care unit (PACU) opioid use. In addition, intraoperative hemodynamic parameters, including systolic pressure, diastolic pressure, mean arterial pressure, and heart rate, were recorded. The severity of postoperative nausea and vomiting (PONV) was also recorded and well managed. Other adverse reactions associated with local nerve block were also documented and managed.

\section{Statistical Analysis}

IBM SPSS for Windows ${ }^{\circledR}$ version 23.0 (SPSS, Chicago, IL, USA) was used for all statistical analyses. Statistical methods (mean, median, minimum-maximum, and rate) were used to evaluate descriptive variables. The Kolmogorov-Smirnov tests of normality were used to verify the normal distribution of quantitative data. Wilcoxon rank sum test was used since the variables were not normally distributed. A single-factor analysis of variance for repeated measurements was used to assess intraoperative blood pressure and heart rate. Fisher's exact and Pearson's chi-square tests were used to compare categorical variables between groups. All 
calculations were two-sided, and the confidence interval was $95 \%$. A bilateral $P$ value of $<0.05$ was considered statistically significant.

\section{RESULTS}

A total of 75 patients who underwent modified radical mastectomy were assessed as eligible, 15 of whom were excluded; 60 patients were randomly divided into two groups (Fig. 2).

The demographic data, duration of anesthesia, site of surgery, operation time, intraoperative dosage of propofol, and hospital stay between the two groups were similar. The intraoperative dosages of remifentanil and sufentanil were lower in group DR than that in group R $(P<0.05)$. Then, PACU stay of patients was longer in group $D R$ than in group $R$ (Table 1).

The VAS pain score was lower in group DR than in group $\mathrm{R}$ at any time in the resting state, except at $1 \mathrm{~h}$ after surgery. The VAS pain score was lower in group DR than in group $\mathrm{R}$ at 12 and $24 \mathrm{~h}$ after surgery (Table 2). During the operation, the heart rate of patients in group DR was lower than that in group R. No statistically significant difference was found in blood pressure between the two groups (Fig. 3). The grouping (group $\mathrm{R}$ or group DR) had a significant effect on heart rate over time (excluding baseline differences) $(P=0.012)$. There was no difference in heart rate between the two groups at baseline $(P=0.682)$. The heart rate of group DR was lower than that of group R after anesthesia induction, pericarpectomy, and axillary dissection and at the end of surgery.

Notably, four patients in group $\mathrm{R}$ had postoperative nausea, and two of them had vomiting. In group DR, two patients developed nausea, and none vomited. However, these differences were not statistically significant between the two groups (postoperative nausea, Fisher's exact chi-square test, $P=0.671$; vomiting, Fisher's exact chi-square test, $P=0.492$ ) (Table 3). After surgery, no sinus bradycardia,

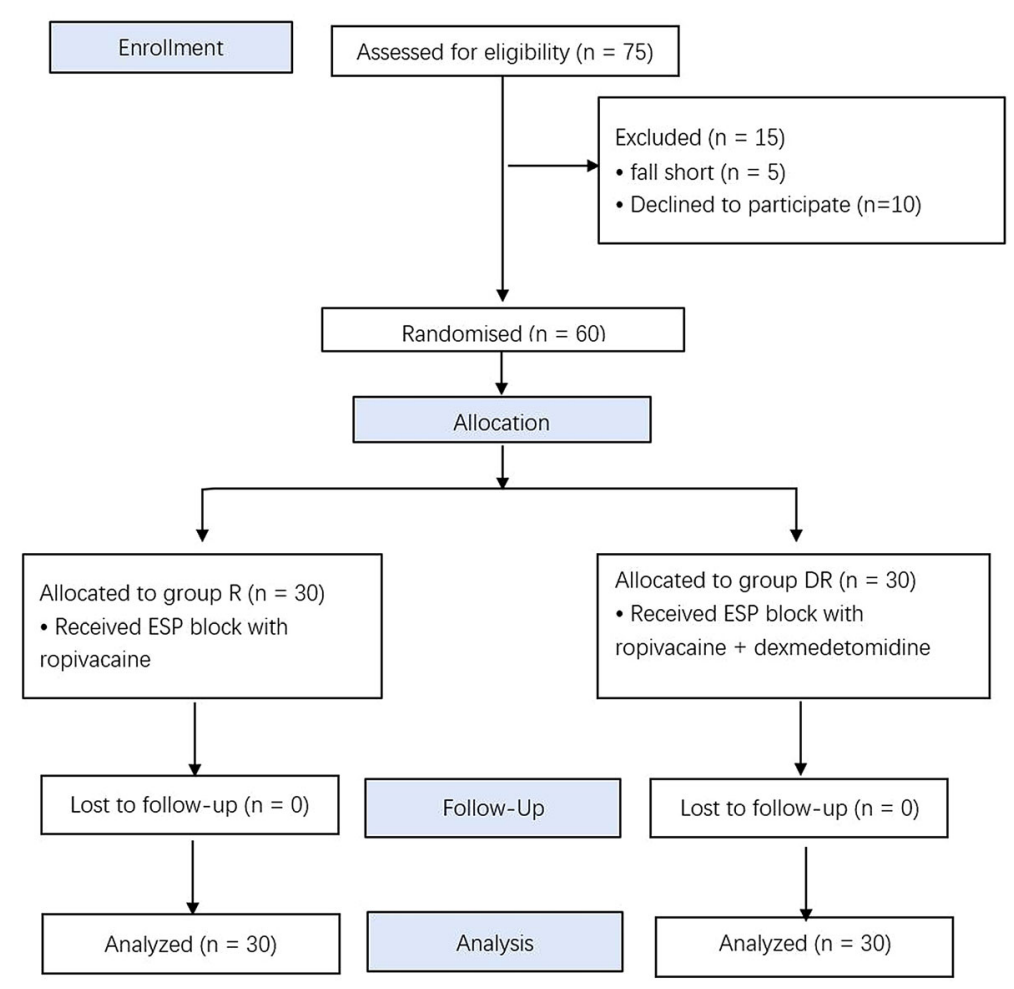

Fig. 2 CONSORT flow of clinical procedures for the study. Group R: erector spinae plane block with ropivacaine; group DR: erector spinae plane block with dexmedetomidine plus ropivacaine 
Table 1 Demographic information of patients and anesthesia during the operation

\begin{tabular}{|c|c|c|}
\hline & $\begin{array}{l}\text { Group R } \\
(n=30)\end{array}$ & $\begin{array}{l}\text { Group DR } \\
(n=30)\end{array}$ \\
\hline Age (year) & $52.83 \pm 8.76$ & $51.93 \pm 9.18$ \\
\hline Height $(\mathrm{cm})$ & $158 \pm 3.99$ & $159 \pm 6.23$ \\
\hline Weight (kg) & $60.07 \pm 7.76$ & $58.73 \pm 6.23$ \\
\hline BMI $\left(\mathrm{kg} / \mathrm{m}^{2}\right)$ & $24.02 \pm 2.80$ & $23.17 \pm 2.43$ \\
\hline ASA (I/II) & $14 / 16$ & $12 / 18$ \\
\hline $\begin{array}{l}\text { Site of surgery (left/ } \\
\text { right) }\end{array}$ & $18 / 12$ & $17 / 13$ \\
\hline $\begin{array}{l}\text { Duration of surgery } \\
(\min )\end{array}$ & $87.50 \pm 20.63$ & $89.20 \pm 25.52$ \\
\hline $\begin{array}{l}\text { Duration of } \\
\text { anesthesia (min) }\end{array}$ & $111.43 \pm 24.16$ & $112.80 \pm 28.59$ \\
\hline $\begin{array}{l}\text { Intraoperative } \\
\text { propofol (mg) }\end{array}$ & $462.6 \pm 112.1$ & $461.7 \pm 108.6$ \\
\hline $\begin{array}{l}\text { Intraoperative } \\
\text { sufentanil }(\mu \mathrm{g})\end{array}$ & $30(20-35)$ & $25(20-30)$ \\
\hline $\begin{array}{l}\text { Intraoperative } \\
\quad \text { remifentanil }(\mu \mathrm{g})\end{array}$ & $75(0-750)$ & 0 \\
\hline PACU stay (min) & $30(24-45)$ & $34.5(29-48)$ \\
\hline Length of stay (days) & $8(6-15)$ & $8(6-18)$ \\
\hline
\end{tabular}

Data are expressed as mean \pm standard deviation, [(Median) Min - Max] or number

$B M I$ body mass index, ASA American Society of Anesthesiologists

hypotension, or other nerve block complications occurred in the two groups. Dexmedetomidine significantly reduced flurbiprofen consumption $(P=0.038)$ after surgery (Table 3$)$.

\section{DISCUSSION}

ESPB is deemed a feasible peripheral nerve block for postoperative analgesia in breast cancer surgery [11]. Because indwelling peripheral nerve catheterization is neither ideal nor easy to manage, the analgesic effect of single
Table 2 Postoperative VAS scores

\begin{tabular}{llll}
\hline & $\begin{array}{l}\text { Group R } \\
(\boldsymbol{n}=\mathbf{3 0})\end{array}$ & $\begin{array}{l}\text { Group DR } \\
(\boldsymbol{n}=\mathbf{3 0})\end{array}$ & $\boldsymbol{P}$ \\
\hline VAS score in rest & & & \\
1st hour & $0(0-1)$ & $0(0-0)$ & 0.159 \\
6th hour & $1(1-1)$ & $1(1-1)$ & 0.002 \\
12th hour & $1.5(1-2)$ & $1(1-1)$ & 0.004 \\
24th hour & $2(1-2)$ & $1(1-1)$ & 0.002 \\
48th hour & $1(1-2)$ & $1(1-1)$ & 0.019 \\
VAS score in & & & \\
movement & & $1(1-1)$ & 0.210 \\
1st hour & $1(1-1)$ & $1(1-1)$ & 0.192 \\
6th hour & $1(1-2)$ & $2(1-2)$ & 0.013 \\
12th hour & $2.5(2-3)$ & $3(2-3)$ & 0.008 \\
24th hour & $3(3-3)$ & $2(2-3)$ & 0.476 \\
48th hour & $3(2-3)$ & & \\
\hline
\end{tabular}

Data were expressed as median and 95\% CI for median, and VAS scores were compared using Wilcoxon rank sum test

postoperative nerve block still needs to be further elucidated. Ropivacaine, a long-acting amide local anesthetic agent, is considered better at separating sensory and motor effects, with less cardiac toxicity. However, ropivacaine alone is used for a short time in nerve block and has limited effect in postoperative analgesia. It was found that dexmedetomidine combined with ropivacaine could enhance peripheral nerve block and prolong sensory block time $[19,20]$.

In this study, we found that ropivacaine with dexmedetomidine $\left(1 \mu \mathrm{g} / \mathrm{kg}^{-1}\right)$ had better analgesic effect than ropivacaine alone. In this study, the postoperative pain score was significantly lower in group DR than that in group $\mathrm{R}$ in both resting and active states. For the breast cancer, ESPB with the combination of dexmedetomidine and ropivacaine could effectively control the postoperative pain up to $24 \mathrm{~h}$. A previous study reported that the addition of dexmedetomidine to ropivacaine increased the 

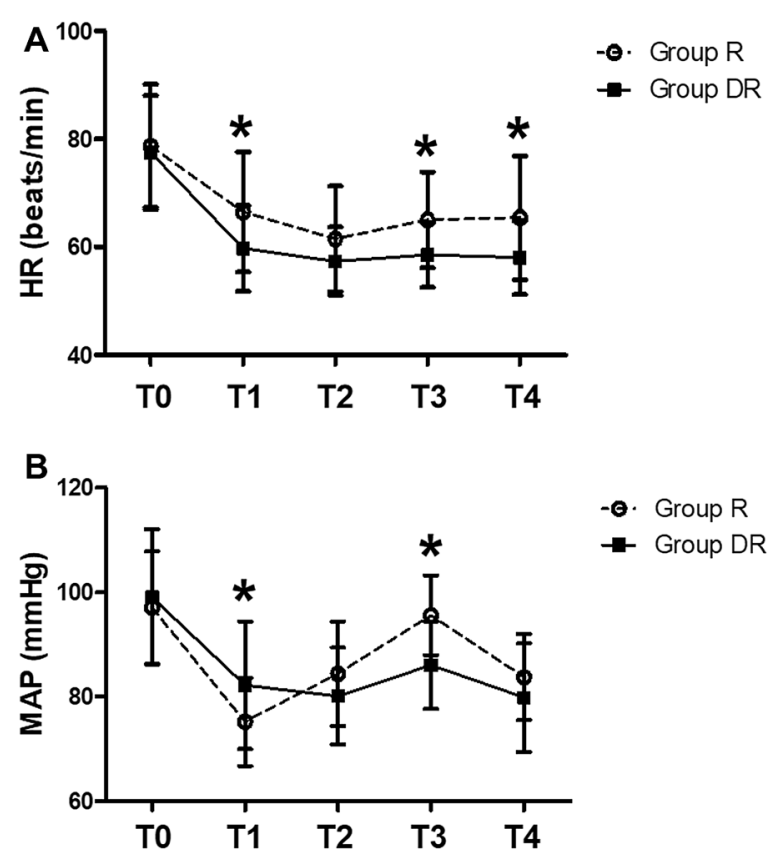

Fig. 3 Changes in hemodynamics. Group R: erector spinae plane block with ropivacaine; group DR: erector spinae plane block with dexmedetomidine plus ropivacaine; a: HR (beats/min); b: MAP (mmHg); HR heart rate; $M A P$ mean arterial blood pressure; TO baseline level when entering the operating room; $T 1$ immediately after anesthesia induction; $T 2$ immediately after incision; $T 3$ immediately after axillary lymph node dissection; $T 4$ end of the surgery. ${ }^{*} P<0.05$ compared with group $\mathrm{R}$

Table 3 Postoperative flurbiprofen consumption and adverse effects

\begin{tabular}{|c|c|c|c|}
\hline & $\begin{array}{l}\text { Group R } \\
(n=30)\end{array}$ & $\begin{array}{l}\text { Group DR } \\
(n=30)\end{array}$ & $P$ \\
\hline $\begin{array}{l}\text { Flurbiprofen } \\
\text { consumption, mg }\end{array}$ & $\begin{array}{l}150 \\
\quad(94-160)\end{array}$ & $\begin{array}{l}100 \\
\quad(52-115)\end{array}$ & 0.038 \\
\hline Nausea & $4(13.3)$ & $2(6.6)$ & 0.671 \\
\hline Vomit & $2(6.6)$ & $0(0)$ & 0.492 \\
\hline Bradycardia & 0 & 0 & - \\
\hline Hypotension & 0 & 0 & - \\
\hline
\end{tabular}

Data are expressed as median and 95\% CI for median, or number (\%)

duration of sensory and motor blockade in a concentration-dependent manner in rats [21].

Reducing perioperative opioid demand is one of the goals of the current enhanced

rehabilitation program. The aim is to reduce the potential side effects associated with opioids. Regional nerve block plays an important role in reducing opioids. Thoracic paravertebral block reduces many complications of epidural block in patients who have had breast surgery [3]. Studies have indicated that thoracic paravertebral block reduces the opioid consumption after breast surgery, and its effect is seen in the early postoperative period, which may be related to the anesthetic time of ropivacaine [22]. ESPB can be given unilaterally during modified radical mastectomy. The anesthesia is similar to thoracic epidural block, but there are no hemodynamic side effects, and ESPB has been found to reduce opioid use after breast cancer surgery [11]. In a recent study, dexmedetomidine combined with paravertebral block was found to have reduced opioid requirement during a video-assisted thoracoscopic surgery [23]. In this study, the consumption of opioids, including sufentanil and remifentanil, in group DR was lower than that in group R; however, this is not enough to make a difference in the postoperative PONV incidence.

Dexmedetomidine has an anti-sympathetic effect and can activate the vagus nerve, reducing plasma catecholamine levels, thereby providing stable hemodynamics and lowering blood pressure and heart rate [24]. Heart rate was lower in group DR than in group R. Mean arterial pressure was similar in both groups inside the operating room. There was no difference in ephedrine and atropine dosage and hemodynamic management between the two groups. Intraoperative bradycardia is only temporary and can be quickly managed with atropine when the heart rate is below 50 beats per minute. No bradycardia occurred in the two groups after surgery. Some studies have reported that adding dexmedetomidine lowers blood pressure and heart rate [25], whereas others have not $[26,27]$. Therefore, the dose relationship between dexmedetomidine and hemodynamic effects is unclear.

The analgesic effects of dexmedetomidine are influenced by a variety of mechanisms. The lower postoperative pain score and reduced opioid consumption during the perioperative period are considered a combination of 
multiple mechanisms. The mechanism of perineural dexmedetomidine is mainly the enhancement of membrane hyperpolarization owing to the activation of sodium and potassium pumps $[28,29]$. The analgesic effect of perineuronal dexmedetomidine is due to the enhancement of cation channels activated by hyperpolarization, which prevents the membrane potential of the nerve from returning from hyperpolarization to the resting state for subsequent discharge [21]. Perineural dexmedetomidine extended the duration of ulnar nerve sensory block by $60 \%$, and systemic dexmedetomidine extended sensory block by 10\% compared with placebo [26]. Therefore, local anesthetic agents combined with dexmedetomidine enhance the inhibition of nerve conduction and produce better analgesic effects than local anesthetic agents alone.

There are some limitations in this study. First, this study lacks an intravenous control. Without an intravenous control, we cannot determine whether dexmedetomidine is added by systemic absorption or by peripheral nerve action. Thus, it is difficult to conclude the exact mechanism by which adjuvant dexmedetomidine has opioid-sparing effects on ESPB. The study also did not evaluate the skin diffusion of the blocker preoperatively to represent its analgesic effect. The diffusion of analgesia and local anesthesia may not be inconsistent.

\section{CONCLUSIONS}

In conclusion, this study reveals that $1 \mu \mathrm{g} / \mathrm{kg}^{-1}$ of dexmedetomidine combined with $0.33 \%$ ropivacaine ESPB can better provide postoperative analgesia than without dexmedetomidine performance, thus improving postoperative analgesia and comfort level.

\section{ACKNOWLEDGEMENTS}

We thank our colleagues for their help in this study, and also thank the participants of the study.
Funding. This work and the article processing fees were funded by the Natural Science Foundation of Anhui Province for Outstanding Youth (2008085J34) and the National Natural Science Foundation of China (No. 81770295).

Authorship. All named authors meet the International Committee of Medical Journal Editors (ICMJE) criteria for authorship for this article, take responsibility for the integrity of the work as a whole, and have given their approval for this version to be published.

Authorship Contributions. All authors contributed to data analysis, drafting or revising the article, gave final approval of the version to be published, and agree to be accountable for all aspects of the work. Xunxun Wang and Guo Ran contributed equally to this work.

Disclosures. Xunxun Wang, Guo Ran, Xia Chen, Cuiyu Xie, Jing Wang, Xuesheng Liu, Yao $\mathrm{Lu}$, and Weiping Fang have nothing to disclose.

Compliance with Ethics Guidelines. The study protocol was conducted at the First Affiliated Hospital of Anhui Medical University from May to August 2020 in accordance with the Declaration of Helsinki. The study was approved by the hospital's research ethics committee (The First Affiliated Hospital of Anhui Medical University Ethics Committee, PJ2020-06-08) and was registered in the Chinese Clinical Trial Registry (ChiCTR2000031134, Principal investigator: Yao Lu, Date of registration: 2020-3-22). Written informed consent was obtained from all participants in this study.

Data Availability. The datasets generated during and/or analyzed during the current study are available from the corresponding author on reasonable request.

Open Access. This article is licensed under a Creative Commons Attribution-NonCommercial 4.0 International License, which permits any non-commercial use, sharing, adaptation, distribution and reproduction in any medium or format, as long as you give appropriate credit to the original author(s) and the source, provide 
a link to the Creative Commons licence, and indicate if changes were made. The images or other third party material in this article are included in the article's Creative Commons licence, unless indicated otherwise in a credit line to the material. If material is not included in the article's Creative Commons licence and your intended use is not permitted by statutory regulation or exceeds the permitted use, you will need to obtain permission directly from the copyright holder. To view a copy of this licence, visit http://creativecommons.org/licenses/by$\mathrm{nc} / 4.0 /$.

\section{REFERENCES}

1. DeSantis C, Ma J, Bryan L, Jemal A. Breast cancer statistics, 2013. CA Cancer J Clin. 2014;64(1):52-62.

2. Macdonald L, Bruce J, Scott NW, et al. Long-term follow-up of breast cancer survivors with postmastectomy pain syndrome. Br J Cancer. 2005;92: 225-30.

3. Woodworth GE, Ivie RMJ, Nelson SM, et al. Perioperative breast analgesia: a qualitative review of anatomy and regional techniques. Reg Anesth Pain Med. 2017;42:609-31.

4. Doss NW, Ipe J, Crimi T, et al. Continuous thoracic epidural anaesthesia with $0.2 \%$ ropivacaine versus general anaesthesia for perioperative management of modified radical mastectomy. Anesth Analg. 2001;92:1552-7.

5. Kaya M, Oğuz G, Şenel G, et al. Postoperative analgesia after modified radical mastectomy: The efficacy of interscalene brachial plexus block. J Anesth. 2013;27:862-7.

6. Kairaluoma PM, Bachmann MS, Korpinen AK, et al. Single injection paravertebral block before general anesthesia enhances analgesia after breast cancer surgery with and without associated lymph node biopsy. Anesth Analg. 2004;99:1837-43.

7. Blanco R. The 'pecs block': a novel technique for providing analgesia after breast surgery. Anesthesia. 2011;66:847-8.

8. Forero M, Adhikary SD, Lopez H, et al. The erector spinae plane block. Reg Anesth Pain Med. 2016;41(5):621-7.
9. Singh S, Chowdhary NK. Erector spinae plane block an effective block for postoperative analgesia in modified radical mastectomy. Indian $\mathrm{J}$ Anaesth. 2018;62(2):148-50.

10. Kwon WJ, Bang SU, Sun WY, et al. Erector spinae plane block for effective analgesia after total mastectomy with sentinel or axillary lymph node dissection: a report of three cases. J Korean Med Sci. 2018;33(45):e291.

11. Gürkan Y, Aksu C, Kuş A, et al. Ultrasound guided erector spinae plane block reduces postoperative opioid consumption following breast surgery: a randomized controlled study. J Clin Anesth. 2018;50:65-8.

12. Fritsch $\mathrm{G}$, Danninger $\mathrm{T}$, Allerberger $\mathrm{K}$, et al. Dexmedetomidine added to ropivacaine extends the duration of interscalene brachial plexus blocks for elective shoulder surgery when compared with ropivacaine alone. Reg Anesth Pain Med. 2014;39(1):37-47.

13. Kamibayashi T, Maze M. Clinical uses of alpha2 adrenergic agonists. Anesthesiology. 2000;93: 1345-9.

14. Vorobeichik L, Brull R, Abdallah FW. Evidence basis for using perineural dexmedetomidine to enhance the quality of brachial plexus nerve blocks: a systematic review and meta-analysis of randomized controlled trials. Br J Anaesth. 2017;118:167-81.

15. Hussain N, Grzywacz VP, Ferreri CA, et al. Investigating the efficacy of dexmedetomidine as an adjuvant to local anesthesia in brachial plexus block: a systematic review and meta-analysis of 18 randomized controlled trials. Reg Anesth Pain Med. 2017;42:184-96.

16. Ping $\mathrm{Y}$, Ye $\mathrm{Q}$, Wang $\mathrm{W}$, et al. Dexmedetomidine as an adjuvant to local anesthetics in brachial plexus blocks: a meta-analysis of randomized controlled trials. Medicine (Baltimore). 2017;96:e5846.

17. $\mathrm{He} \mathrm{W}, \mathrm{Wu} \mathrm{Z}, \mathrm{Zu} \mathrm{L}$, et al. Application of erector spinae plane block guided by ultrasound for postoperative analgesia in breast cancer surgery: a randomized controlled trial. Cancer Commun. 2020;40:122-5.

18. Adhikary SD, Bernard S, Lopez H, et al. Erector spinae plane block versus retrolaminar block: a magnetic resonance imaging and anatomical study. Reg Anesth Pain Med. 2018;43:756-62.

19. Koraki E, Stachtari C, Kapsokalyvas I, et al. Dexmedetomidine as an adjuvant to $0.5 \%$ ropivacaine in ultrasound-guided axillary brachial plexus block. J Clin Pharm Ther. 2018;43:348-52. 
20. Fritsch G, Danninger T, Allerberger K, et al. Added to ropivacaine extends the duration of interscalene brachial plexus blocks for elective shoulder surgery when compared with ropivacaine alone. Reg Anesth Pain Med. 2014;39:37-47.

21. Brummett CM, Padda AK, Amodeo FS, et al. Perineural dexmedetomidine added to ropivacaine causes a dose-dependent increase in the duration of thermal antinociception in sciatic nerve block in rat. Anesthesiology. 2009;111:1111-9.

22. Shimizu H, Kamiya Y, Nishimaki H, et al. Thoracic paravertebral block reduced the incidence of chronic postoperative pain for more than 1 year after breast cancer surgery. JA Clin Rep. 2015;11:19.

23. Hong B, Lim C, Kang H, et al. Thoracic paravertebral block with adjuvant dexmedetomidine in video-assisted thoracoscopic surgery: a randomized, Double-Blind Study. J Clin Med. 2019;8:352.

24. Lin $\mathrm{YN}, \mathrm{Li} \mathrm{Q}$, Yang $\mathrm{RM}$, et al. Addition of dexmedetomidine to ropivacaine improves cervical plexus block. Acta Anaesthesiol Taiwan. 2013;51: 63-6.
25. Esmaoglu A, Yegenoglu F, Akin A, et al. Dexmedetomidine added to levobupivacaine prolongs axillary brachial plexus block. Anesth Analg. 2010;111:1548-51.

26. Marhofer D, Kettner SC, Marhofer $\mathrm{P}$, et al. Dexmedetomidine as an adjuvant to ropivacaine prolongs peripheral nerve block: a volunteer study. Br J Anaesth. 2013;110:438-42.

27. Obayah GM, Refaie A, Aboushanab O, et al. Addition of dexmedetomidine to bupivacaine for greater palatine nerve block prolongs postoperative analgesia after cleft palate repair. Eur J Anaesthesiol. 2010;27:280-4.

28. Malmberg AB, Hedley LR, Jasper JR, et al. Contribution of alpha (2) receptor subtypes to nerve injury-induced pain and its regulation by dexmedetomidine. $\mathrm{Br}$ J Pharmacol. 2001;132: 1827-36.

29. Dalle C, Schneider M, Clergue F, et al. Inhibition of the I(h) current in isolated peripheral nerve: a novel mode of peripheral antinociception? Muscle Nerve. 2001;24:254-61. 